\title{
GAMBARAN FAKTOR-FAKTOR TENTANG PEMILIHAN PERTOLONGAN PERSALINAN OLEH TENAGA KESEHATAN DI WILAYAH KERJA PUSKESMAS MAPILLI KABUPATEN POLEWALI MANDAR
}

\author{
ROSDIANA
}

Latar Belakang: Pemanfaatan penolong persalinan oleh tenaga kesehatan profesional (bidan) di masyarakat masih sangat rendah dibandingkan indikator yang diharapkan. Hal ini disebabkan oleh factor ibu seperti pengetahuan, social ekonomi, pendidikan dan sikap dalam mengambil keputusan untuk memanfaatkan tenaga kesehatan ahli dalam pertolongan persalinan serta jangkauan ke pelayanan kesehatan. Tujuan penelitian ini adalah untuk mengetahui gambaran factor-faktor yang mempengaruhi pemilihan pertolongan persalinan dari segi pengetahuan, pendidikan, penghasilan, dan sikap terhadap pelayanan oleh tenaga kesehatan khususnyatentang pertolongan persalinan.

Metode penelitian ini adalah kuantitatif dengan jenis penelitian deskriptif, dengan sampel adalah ibu bersalin tahun 2014 baik yang bersalin di Nakes maupun Non-Nakes. Jumlah Populasi sebayak 471 ibu bersalin dimana jumlah sampel sebanyak 82 orang dengan penentuan sampel menggunakan sample random sampling. Data diperoleh dengan wawancara dan menggunakan kuesioner.

Hasil penelitian didapatkan faktor pengetahuan dan sikap berpengaruh terhadap pemilihan pertolongan persalinan sedang faktor pendidikan dan penghasilan tidak berpengaruh terhadap pemilihan pertolongan persalinan.

Kesimpulan: berdasarkan hasil penelitian perlu adanya penyuluhan tentang pentingnya pertolongan persalinan oleh tenaga kesehatan, untuk meningkatkan pengetahuan serta mengubah pola sikap masyarakat menjadi positif terhadap pelayanan oleh tenaga kesehatan khususnya yang berkaitan dengan pertolongan persalinan oleh tenaga kesehatan.

Kata kunci : deskriptif, pemilihan pertolongan persalinan.

\section{PENDAHULUAN}

Persalinan dan kelahiran merupakan kejadian fisiologi yang normal dalam kehidupan (Sumarah, 2008).

Persalinan adalah proses membuka dan menipisnya servik, dan janin turun dalam jalan lahir. kelahiran adalah proses dimana janin dan ketuban di dorong keluar melalui jalan lahir (pelayanan kesehatan maternal dan neonatal, Sarwono:2009).

Pertolongan persalinan oleh tenaga kesehatan adalah pelayanan persalinan yang aman yang dilakukan oleh tenaga kesehatan yang kompeten. Pada kenyataannya di lapangan, masih terdapat penolong persalinan yang bukan tenaga kesehatan dan dilakukan diluar fasilitas pelayanan kesehatan (Depkes RI,2009).

Menurut hasil penelitian dari 97 negara bahwa ada korelasi yang signifikan antara pertolongan persalinan dengan kematian ibu. Semakin tinggi cakupan persalinan oleh tenaga kesehatan disuatu wilayah akan diikuti penurunan kematian ibu diwilayah tersebut. Namun sampai saat ini di wilayah indonesia masih banyak pertolongan persalinan dilakukan oleh dukun yang masih menggunakan caracara tradisional sehingga banyak merugikan dan membahayakan keselmatan ibu dan bayi baru lahir (Wati sufiawati, 2012).

Pelayanan kesehatan maternal dan neonatal merupakan salah satu unsur 
kesehatan, AKI merupakan barometer kemajuan pelayanan kesehatan. Mortalitas sebagai komponen dalam demografi merupakan komponen yang penting untuk diteliti karena memegang peranan penting didalam kelangsungan hidup didalam suatu kelompok masyarakat, apakah akan berkembang, statis, atau gagal untuk bertahan. Kesejahteraan ibu dan anak yang dipengaruhi oleh komponen mortalitas yang terkait erat dengan proses kehamilan, kelahiran dan paska kelahiran. Ketiga periode tersebut akan menentukan kualitas SDM yang akan datang. Kematian ibu masih merupakan masalah besar yang dihadapi berbagai Negara didunia terutama di Negara berkembang, sehingga Indonesia berkomitmen sesuai dengan dekalarasi Millenium Devalopment Goals untuk menurunkan AKI menjadi $1 / 3$ dari keadaan tahun 2000 yaitu menjadi 102 per 100.000 kelahiran hidup pada tahun 2015. Penurunan angka kematian ibu per 100.000 kelahiran hidup masih terlalu lambat untuk mencapai target tujuan pembangunan millennium (Millenium Develpoment Goals/MDGs).

Menurut Organisasi Kesehatan Dunia atau World Health Organization (WHO) menjelaskan bahwa Angka Kematian Ibu (AKI) dan Angka Kematian Bayi (AKB) di indonesia masih tinggi dibandingkan dengan negara ASEAN.

Berdasarkan SDKI 2012 AKI Indonesia sebanyak 359/100.000 kelahiran hidup sedangkan AKB sebesar 40/1000 kelahiran hidup dan AKN adalah 19 per 1000 kelahiran hidup.

Penyebab utama kematian maternal masih disebabkan oleh trias kematian ibu yaitu $28 \%$ perdarahan, $11 \%$ infeksi, $24 \%$ eklamsi,. Sementara penyebab utama kematian perinatal yaitu disebabkan oleh asfiksia neonatorum 27\%, infeksi 5\%, prematuritas BBLR 29\%, dan tetanus neonatorum (Depkes RI, 2007).

AKB di provinsi Sulawesi barat tahun 2012 sebesar 14,5/ 1.000 kelahiran hidup meningkat bila dibandingkan dengan tahun 2011 sebesar 11,6/1.000 kelahiranhidup. Apabila dibandingkan dengan target nasional 24/1000 kelahiran hidup , Maka AKB Provinsi Sulawesi barat sudahmelampaui targetnasinal, demikian juga bila dibandingkan dengan target yang diharapkan dalam MDGs tahun 2015 yaitu 23/1000 kelahiran hidup (Saleh Mandar, 2012).

Angka Kematian Ibu di Polewali Mandar tahun 2014 yaitu 65/100.000 kelahiran hidup sedang Angka Kematian Bayi yaitu 11/1.000 kelahiran hidup.

Jumlah AKI dan AKB Pada tahun 2014 di Puskesmas Mapilli yaitu terdapat1 kematian ibu dan 4 kematian bayi.(Profil Puskesmas,2014).

Salah satu indikator derajat kesehatan masyarakat adalah angka kematian ibu (AKI). Makin tinggi AKI menunjukkan bahwa derajat kesehatan dapat dikategorikan buruk dan belum berhasil dalam meningkatkan derajat kesehatan masyarakat yang setinggitingginya (DepKes RI, 2007).

Untuk mengatasi masalah ini, pemerintah Indonesia melalui Departemen Kesehatan telah mengeluarkan kebijakan pendekatan pelayanan kesehatan ibu dan bayi baru lahir berkualitas kepada masyarakat melalui Making Pregnancy Safer (MPS). Salah satu target MPS yang ditetapkan untuk tahun 2010 adalah meningkatkan cakupan persalinan yang ditolong oleh tenaga kesehatan terampil menjadi 90\%. Salah satu strategi untuk mencapai target tersebut diatas adalah meningkatkan akses dan cakupan pelayanan kesehatan ibu dan bayi baru lahir berkualitas yang costefective dan berdasarkan bukti-bukti (Depkes RI, 2009). 
Di Polewali Mandar tahun 2014 jumlah ibu bersalin yaitu 9461 jiwa dimana persalinan yang ditolong oleh Nakes yaitu $7457(78,8 \%)$ jiwa dan $2004(21,2 \%)$ jiwa oleh Non nakes ( Dinkes Polewali Mandar, 2014).

Pada tahun 2014 jumlah persalinan di Puskesmas Mapilli sebanyak 471 orang dimana 401 $(85,1 \%)$ diantaranya ditolong oleh Nakes dan $70(14,9 \%)$ lainnya ditolong oleh Non Nakes/dukun (Profil Puskesmas Mapilli,2014).

Menurut penelitian Juliwanto (2008) bahwa Pemanfaatan penolong persalinan oleh tenaga kesehatan profesional (bidan) di masyarakat masih sangat rendah dibandingkan indikator yang diharapkan. Hal ini disebabkan oleh factor ibu seperti pengetahuan, social ekonomi, sikap dalam mengambil keputusan untuk memanfaatkan tenaga kesehatan ahli dalam pertolongan persalinan serta jangkauan ke pelayanan kesehatan

\section{METODE PENELITIAN}

\section{Jenis dan Metode Penelitian}

Penelitian ini menggunakan metode penelitian deskriptif. Penelitian ini dilakukan untuk mendapatkan gambaran factor-faktor tentang pemilihan pertolongan persalinan oleh tenaga kesehatan di Wilayah Kerja Puskesmas Mapilli Kecamatan Mapilli.

\section{Lokasi dan Waktu Penelitian}

HASIL DAN PEMBAHASAN

\section{Hasil Penelitian}

Rendahnya cakupan persalinan yang ditolong oleh tenaga kesehatan dapat dipengaruhi oleh sikap dan perilaku ibu dalam memilih tenaga penolong persalinan. Menurut teori Health beliefe model yang dikembangkan oleh Rosenstock(1950) dalam Noto Admodjo (2007), kemungkinan individu untuk mengambil tindakan tepat untuk perilaku sehat/sakit dipengaruhi oleh: (1) keyakinan tentang kerentanan individu terhadap keadaan sakit; (2) keyakinan tentang keseriusan atau keganasan penyakit; (3) keyakinan tentang manfaat; dan (4) isyarat atau petunjuk aksi (Cuest) (Notoatmodjo, 2007).

Dari data tersebut maka penulis tertarik untuk mengetahui bagaimana gambaran faktor-faktor tentang pemilihan pertolongan persalinan oleh tenaga kesehatan di Wilayah kerja Puskesmas Mapilli Kabupaten Polewali Mandar.

Penelitian ini dilakukan di wilayah kerja puskesmas Mapilli pada bulan September Tahun 2017.Populasi dan Sampel

Populasi dalam penelitian ini adalah Semua ibu yang bersalin pada bulan januari - Agustus tahun 2017 di Wilayah Kerja Puskesmas Mapilli Kecamatan Mapilli Kabupaten Polman yaitu 471 ibu. Jumlah sampel dalam penelitian ini adalah 82 orang.

Tabel 4.1

Distribusi Frekuensi Responden Menurut Kelompok Umur di Wilayah kerja Puskesmas Mapilli Kecamatan Mapilli

\begin{tabular}{|l|l|l|l|}
\hline No & Umur Responden & Frekuensi & $\%$ \\
\hline 1 & $<20$ tahun & 2 & 2,4 \\
2 & $20-35$ tahun & 61 & 74,4 \\
3 & $>35$ tahun & 19 & 23,2 \\
\hline \multicolumn{2}{|l|}{ Total } & 82 & 100 \\
\hline
\end{tabular}

Sumber : Data Primer, 2017 
Berdasarkan tabel 4.1 tentang umur responden, dimana hasil penelitian menunjukkan bahwa dari 82 responden, yang berusia $<20$ tahun sebanyak 2 responden atau
(2,4\%), yang berusia 20-35 tahun sebanyak 61 responden atau $(74,4 \%)$, dan yang berusia > 35 tahun sebanyak 19 responden atau ( $23,2 \%)$.

Tabel 4.2

Distribusi Responden Berdasarkan Pekerjaan

Di Wilayah Kerja Puskesmas Mapilli

\begin{tabular}{|l|l|l|l|}
\hline No & Pekerjaan & Frekuensi & $\%$ \\
\hline 1 & PNS & 1 & 1,2 \\
2 & Honorer & 3 & 3,6 \\
3 & Wiraswasta & 1 & 1,2 \\
4 & Tidak Bekerja & 77 & 94 \\
\hline \multicolumn{2}{|l|}{ Total } & 82 & 100 \\
\hline
\end{tabular}

Sumber : Data Primer, 2017

Berdasarkan tabel 4.2 tentang pekerjaan responden, dimana hasil penelitian menunjukkan bahwa dari 82 responden, yang tidak bekerja sebanyak 77 responden atau (94\%), yang bekerja sebagai wiraswasta

\section{Variabel Yang Diteliti}

sebanyak 1 responden atau $(1,2 \%)$. yang bekerja sebagai PNS 1 sebanyak responden atau $(1,2 \%)$, dan yang bekerja sebagai honorer sebanyak 3 responden atau $(3,6 \%)$.

Tabel 4.3

Distribusi Frekuensi Pemilihan Pertolongan Persalinan oleh Ibu Bersalin

\begin{tabular}{|l|l|l|l|}
\hline No & Kategori & Frekuensi & Persentase (\%) \\
\hline 1 & Nakes & 71 & 86,5 \\
2 & Non Nakes & 11 & 13,5 \\
\hline \multicolumn{2}{|c|}{ Jumlah } & 82 & 100 \\
\hline
\end{tabular}

Sumber : Data Primer, 2017

Berdasarkan Tabel 4.3 menunjukkan bahwa pemilihan pertolongan persalinan oleh ibu bersalin, dimana hasil penelitian menunjukkan bahwa dari 82 responden yang memilih bersalin di Nakes sebanyak 71 responden atau $(86,5 \%)$ dan yang memilih bersalin di Non Nakes sebanyak 11 orang atau $(13,5 \%)$.

Tabel 4.4

Distribusi Frekuensi Tingkat Pengetahuan Responden

Tentang pemilihan pertolongan persalinan. 


\begin{tabular}{|l|l|l|l|}
\hline No & Kategori & Frekuensi & $(\%)$ \\
\hline 1 & Baik & 22 & 26,8 \\
2 & Cukup & 46 & 56,1 \\
3 & Kurang & 14 & 17,1 \\
\hline \multicolumn{2}{|c|}{ Jumlah } & 82 & 100 \\
\hline
\end{tabular}

Sumber : Data Primer 2017

Berdasarkan Tabel $\quad 4.4$ menunjukkan bahwa pengetahuan responden ibu bersalin tentang pemilihan pertolongan persalinan, dimana hasil penelitian menunjukkan bahwa dari 82 responden yang memperoleh kriteria baik sebanyak 22 responden atau $(26,8 \%)$, yang memperoleh kriteria cukup sebanyak 46 responden atau $(56,1 \%)$, dan yang mempunyai kriteria kurang sebanyak 14 responden atau $(17,1 \%)$.

Tabel 4.5

\section{Distribusi Frekuensi Tingkat Pendidikan Responden Tentang pemilihan pertolongan persalinan}

\begin{tabular}{|l|l|l|l|}
\hline No & Pendidikan & Frekuensi & $\%$ \\
\hline 1 & Rendah: & & \\
& TS & 3 & 3,6 \\
& SD & 47 & 57,3 \\
2 & Menengah: & & \\
& SMP & 21 & 25,6 \\
& SMA & 7 & 8,5 \\
3 & Tinggi & & 4,8 \\
& PT/AK & 4 & 100 \\
\hline
\end{tabular}

Sumber : Data Primer, 2015

Berdasarkan tabel 4.5 tentang pendidikan responden, dimana hasil penelitian menunjukkan bahwa dari 82 responden, yang tidak sekolah sebanyak 3 responden atau $(3,6 \%)$, berpendidikan SD sebanyak 47 responden atau (57,3\%), yang berpendidikan SMP sebanyak 21 responden atau $(25,6 \%)$, yang berpendidikan SMA sebanyak 7 responden atau $(8,5 \%)$, yang berpendidikan AK (Akademi)/PT sebanyak 4 responden atau $(4,8 \%)$.

Tabel 4.6

Distribusi Frekuensi Tingkat penghasilan Responden Tentang pemilihan pertolongan persalinan. 


\begin{tabular}{|l|l|l|l|}
\hline No & Penghasilan & Frekuensi & $\%$ \\
\hline 1 & $>$ UMR & 10 & 12,2 \\
2 & <UMR & 72 & 87,8 \\
\hline \multicolumn{2}{|l|}{ Total } & 82 & 100 \\
\hline
\end{tabular}

Sumber : Data Primer, 2015

Berdasarkan tabel 4.6 tentang penghasilan keluarga responden, dimana hasil penelitian menunjukkan bahwa dari 82 responden, yang berpenghasilan
$>$ UMR sebanyak 10 responden atau $(12,2 \%)$, dan yang berpenghasilan $<$ UMR sebanyak 72 responden atau $(87,8 \%)$.

Tabel 4.7

Distribusi Frekuensi Sikap Ibu Bersalin / Keluarga Tentang pemilihan pertolongan persalinan

\begin{tabular}{|l|l|l|l|}
\hline No & Kategori & Frekuensi & $\%$ \\
\hline 1 & Positif & 69 & 84 \\
2 & Negatif & 13 & 16 \\
& & & \\
\hline \multicolumn{2}{|l|}{ Total } & 82 & 100 \\
\hline
\end{tabular}

Sumber : Data Primer, 2017

\begin{abstract}
Berdasarkan Tabel $\quad 4.7$ menunjukkan bahwa sikap responden/keluarga tentang tenaga penolong persalinan, dimana hasil penelitian menunjukkan bahwa dari
\end{abstract}

\subsection{PEMBAHASAN}

\subsubsection{Pemilihan Pertolongan Persalinan oleh ibu bersalin dari segi pengetahuan.}

Pengetahuan adalah hasil pengindraan manusia, atau hasil tahu seseorang terhadap objek melalui indra yang dimilikinya (mata, hidung, telinga, dan sebagainya). Sebagian besar pengetahuan seseorang diperoleh melalui indra pendengaran (telinga), dan indra penglihatan (mata). Pengetahuan seseorang terhadap objek mempunyai intensitas atau tingkat yang berbeda-beda (Notoatmodjo, 2010).

Dari hasil penelitian diperoleh bahwa tingkat
82 responden yang memperoleh kriteria positif sebanyak 69 responden atau (84\%), yang memperoleh kriteria negative sebanyak 13 responden atau (16\%).

pengetahuan responden ibu bersalin tentang pemilihan pertolongan persalinan, dimana hasil penelitian menunjukkan bahwa dari 82 responden yang memperoleh kriteria baik sebanyak 22 responden atau (26,8\%), yang memperoleh kriteria cukup sebanyak 46 responden atau $(56,1 \%)$, dan yang mempunyai kriteria kurang sebanyak 14 responden atau $(17,1 \%)$. Sebagian besar tingkat pengetahuan responden berada pada kategori cukup dan memilih tenaga kesehatan sebagai penolong persalinan.

Hasil penelitian ini sejalan dengan teori yang dikemukakan oleh Rohmah 
(2010) yaitu Pemilihan tempat bersalin dan penolong persalinan yang tidak tepat akan berdampak langsung pada kesehatan ibu. Hal ini bisa dipengaruhi oleh beberapa hal diantaranya pengetahuan untuk mencari persalinan yang aman. Karena pengetahuan tersebut akan mempengaruhi keputusan dalam meminta bantuan pertolongan persalinan.

Hasil Penelitian ini tidak sejalan dengan penelitian yang dilakukan oleh Asriani (2009) menyatakan bahwa besarnya hubungan antara pemanfaatan pertolongan persalinan dengan tingkat pengetahuan yang dihitung dengan menggunakan rumus phi dengan hasil 0,248 dimana hasil uji ini memperlihatkan adanya hubungan yang lemah.

\subsubsection{Pemilihan Pertolongan Persalinan Oleh ibu bersalin dari segi pendidikan.}

Pendidikan yang ditempuh oleh seseorang merupakan salah satu faktor demografi yang sangat berpengaruh terhadap kondisi kesehatan individu maupun masyarakat (Kusmawati, 2006)

Hasil penelitian menunjukkan bahwa dari 82 responden, yang berpendidikan rendah sebanyak 50 responden (tidak sekolah sebanyak 3 responden dan SD sebanyak 47 responden) atau $60,9 \%$, yang berpendidikan

menengah sebanyak 28

responden (SMP sebanyak 21 responden dan berpendidikan SMA sebanyak 7 responden) atau $34,1 \%$, dan yang berpendidikan AK (Akademi)/PT sebanyak 4 responden atau (4,8\%). Sebagian besar responden berpendidikan rendah dan memilih tenaga kesehatan sebagai penolong persalinan.

Hasil Penelitian ini tidak sejalan dengan apa yang dikemukakan oleh Widiawati ( 2008) bahwa tingkat pendidikan mempengaruhi kesadaran terhadap pentingnya kesehatan sehingga mendorong seseorang untuk memanfaatkan pelayanan kesehatan. Seseorang dengan pendidikan tinggi akan lebih senang menggunakan pelayanan kesehatan modern dari pada pelayanan tradisional, karena sudah mendapatkan informasi tentang keuntungan dan kerugiannya.

Hasil penelitian ini juga tidak sejalan dengan penelitian serupa dilakukan oleh Andi Adni Pratiwi(2014) yang menyatakan bahwa ada hubungan antara tingkat pendidikan dengan pemanfaatan pertolongan persalinan oleh tenaga kesehatan. Hasil analisis chisquare dengan continuity Correction diperoleh nilai $\mathrm{p}=$ $0,008(\mathrm{p}<0,005)$ dengan nilai $\varphi=0,337$ yang berarti hubungan sedang. Yang berarti semakin tinggi tingkat 
pendidikan maka semakin tinggi pemanfaatan pertolongan persalinan oleh tenaga kesehatan.

Perlu ditekankan, bukan berarti seseorang yang berpendidikan rendah, mutlak berpengetahuan rendah pula. Hal ini mengingat bahwa peningkatan pengetahuan tidak mutlak diperoleh dari pendidikan formal tetapi juga bisa diperoleh dari pendidikan non formal misalnya mendapat informasi dari televisi, radio, internet, serta penyuluhan.

\subsubsection{Pemilihan Pertolongan Persalinan oleh ibu bersalin dari segi penghasilan suami/keluarga.}

Ditinjau dari status sosial ekonomi, penghasilan merupakan jumlah pendapatan perbulan yang besarnya dipengaruhi oleh status pekerjaan seseorang. Besarnya penghasilan berdampak pada daya beli, sehingga pada keluarga dengan penghasilan besar, kemungkinan untuk memberikan perawatan kesehatan lebih tinggi dibandingkan dengan keluarga dengan penghasilan yang lebih rendah.

Hasil penelitian tentang penghasilan keluarga responden, dimana menunjukkan bahwa dari 82 responden, yang berpenghasilan >UMR sebanyak 10 responden atau $(12,2 \%)$, dan yang berpenghasilan <UMR sebanyak 72 responden atau $(87,8 \%)$. Sebagian besar responden berpenghasilan < UMR dan memilih tenaga kesehatan sebagai penolong persalinan.

Hasil penelitian ini sejalan dengan penelitian yang dilakukan oleh Asriani (2009) yang menyatakan bahwa besarnya hubungan antara pemanfaatan pertolongan persalinan dengan tingkat kemampuan ekonomi dengan menggunakan rumus phi dengan hasil 0,168 dimana hasil uji ini memperlihatkan adanya hubungan yang lemah.

\subsubsection{Pemilihan Pertolongan Persalinan oleh ibu bersalin dari segi sikap.}

Sikap adalah respon tertutup seseorang terhadap stimulus atau objek tertentu, yang sudah melibatkan factor pendapat dan emosi yang bersangkutan. Adalah bagaimana pendapat atau penilaian orang atau responden terhadap hal yang terkait dengan kesehatan, sehat-sakit, dan factor yang terkait dengan factor resiko kesehatan. Misalnya bagaimana pendapat atau penilaian responden tentang pemilihan tenaga penolon persalinan. (Notoatmodjo, 2010).

Hasil penelitian menunjukkan bahwa sikap responden/keluarga tentang tenaga penolong persalinan, dimana dari 82 responden yang memperoleh kriteria positif sebanyak 69 responden atau (84\%), ng memperoleh kriteria negative sebanyak 13 responden atau (16\%). Sebagian besar 
responden memiliki sikap positif dan memilih tenaga kesehatan sebagai penolong persalinan.

Penelitian ini sejalan dengan penelitian yang dilakukan oleh Andi Adni Pratiwi (2014) yang menyatakan bahwa sikap terhadap pelayanan kesehatan memiliki hubungan dengan pemanfaatan pertolongan persalinan oleh tenaga kesehatan. Hasil analisis chisquare dengan continuity correction diperoleh nilai $\mathrm{p}=0,000 \quad(\mathrm{p}<0,005)$ dengan nilai $\varphi=0,432$ yang berarti hubungan sedang. Yang berarti semakin tinggi pelayanan kesehatan yang diberikan tenaga kesehatan maka semakin tinggi pemanfaatan pertolongan persalinan oleh tenaga kesehatan.

\section{KESIMPULAN DAN SARAN Kesimpulan}

Dari hasil penelitian yang dilakukan terdapat 82 responden tentang faktorfaktor tentang pemilihan pertolongan persalinan oleh tenaga kesehatan diperoleh kesimpulan:

1. Tingkat pengetahuan dari 82 responden rata-rata mempunyai pengetahuan yang cukup yaitu sebanyak 46 orang $(56,1 \%)$.

2. Tingkat pendidikan dari 82 responden rata-rata mempunyai tingkat pengetahuan yang rendah yaitu sebanyak 50 orang $(60,9 \%)$.

3. Tingkat Penghasilan ibu/keluarga dari 82 responden rata-rata mempunyai tingkat dibawah UMR yaitu sebanyak 72 orang $(87,8 \%)$.

4. Gambaran sikap terhadap pemilihan persalinan dari 82 responden rata-rata mempunyai sikap yang positif yaitu 69 orang $(84 \%)$.

\section{DAFTAR PUSTAKA}

Azwar, S. (2006). Metode Penelitian. Yogyakarta: Pustaka Belajar

Chandranita, Dr.idha Ayu SpOG. Ilmu kebidanan, penyakit kandungan dan KB untuk pendidikan bidan. 2005: buku kedokteran EGC

Estiwidani dkk.

Kebidanan. Yogyakarta: Fitramaya

Hidayat. Metode Penelitian Kebidanan dan Analisis Data.2007. Jakarta: Salemba Medika.

http://hanstoe.wordpress.com.2013

JNPK-KR. (2008). Pelatihan Asuhan Persalinan Normal Bahan Tambahan Inisiasi menyusu Dini.Jakarta: JNPK-KR

Johariyah, S.ST, M.Keb dkk, Buku ajar asuhan kebidanan persalinan dan bayi baru lahir.2012:Trans.info media Jakarta.

Juliwanto. E. (2008). Faktor- faktor yang Mempengaruhi Keputusan Memilih Penolong persalinan Pada Ibu Hamil Di Kecamatan Babul Rahman Kabupaten Aceh Tenggara. Available from http://library.usu.ac.id/index.php?. (diakses 14 Februari 2015).

Kurniati, Anna.SDM Kesehatan di Indonesia.2012: Salemba Medica

Lisnawati, Lilis, S.ST., M.Keb,buku praktis kebidanan komunitas.2013. trans info media:Jakarta.

Nursalam.(2008).Konsep dan Penerapan Metodologi Penelitian Ilmu Keperawatan.Jakarta: Salemba Medika. 
Notoadmodjo.S (2010).Metode Penelitian Kesehatan. 2010.Jakarta: Rineka Cipta.

Oxorn, Harry dkk.(2010) ilmu kebidanan patologi dan fisiologi persalinan.: yayasan essential medica.

Prawirohardjo, S.(2007).Ilmu Kebidanan. Jakarta: yayasan Bina Pustaka Sarwono

Prawirohardjo, Sarwono.(2009).Buku Acuan nasional Pelayanan Kesahatan Maternal dan Neonatal.Jakarta: Yayasan Bina Pustaka Sarwono

Rahmaniza.(2012).Gambaran

Karakteristik Pemilihan Penolong Persalinan di Wilayah Kerja Puskesmas Kuta BaroKabupaten Aceh besar.

Setyaningrum, Erna. SST,M.MKes, M.A. Asuhan kegawatdaruratan maternitas (asuhan kebidanan patologi). 2013. In media

Suliastyaningsih (2011). Metodologi Penelitian.Yogyakarta

Suseno,Tutu A, SKP, Etika Profesi Kebidanan.2010, citra pustaka Yogyakarta

Rahmah, N. (2010).Pendidikan perinatal. Jakarta: Gramata Publishing

Tando Naomy Marie. Asuhan kebidanan persalinan dan Bayi Baru Lahir.2013: In media 